\title{
Mapeamento de atributos químicos em diferentes densidades amostrais e influência na adubação e calagem
}

\author{
Diovane Caon ${ }^{1} \&$ Aline M. Genú ${ }^{2}$
}

\begin{abstract}
RESUMO
Como processo inicial de mapeamento a amostragem de solo,quando realizada de forma ineficiente, pode levar a um planejamento errôneo quanto à aplicação de corretivos e fertilizantes. O objetivo do presente trabalho foi estabelecer uma densidade amostral que ofereça precisão nos mapas de atributos químicos gerados sobre diferentes densidades amostrais, em duas profundidades, e mensurar sua implicação prática na adubação e calagem para a cultura da soja, na região de Guarapuava. Foram comparados mapas para $\mathrm{pH}, \mathrm{H}+\mathrm{Al}, \mathrm{P}, \mathrm{K}, \mathrm{Ca}, \mathrm{Mg}, \mathrm{V} \%$ e necessidade de calagem, nas camadas 0-10 e 0-20 cm, nas densidades amostrais de 1/4, 1/2, 1, 2 e 4 ha, sendo a primeira densidade tomada como referência de comparação. Os modos de comparação foram a exatidão global e o índice Kappa. A diminuição da densidade amostral depreciou a qualidade dos mapas gerados. Todas as densidades amostrais diferiram entre si quanto à exatidão porém foram encontrados bons níveis de exatidão até a densidade amostral de uma amostra por hectare. A agricultura de precisão utiliza, de forma mais eficiente, a quantidade de calcário e fertilizantes do que a agricultura convencional.
\end{abstract}

Palavras-chave: agricultura de precisão, Kappa, krigagem

\section{Mapping of chemical attributes in different sampling densities and influence on fertilization and liming}

\begin{abstract}
Soil sampling and initial mapping process, when performed inefficiently, can lead to erroneous planning regarding the application of fertilizers. The objectives of this study were to establish a sampling density that provides accurate maps of the chemical attributes generated for different sampling densities in two depths, and to measure their practical implications in fertilization and liming for soybean on an Oxisol in the region of Guarapuava. Maps were compared for the attributes $\mathrm{pH}, \mathrm{H}+\mathrm{Al}, \mathrm{P}, \mathrm{K}, \mathrm{Ca}, \mathrm{Mg}$, base saturation and the lime requirement, in the layers $0-10$ and $0-20 \mathrm{~cm}$, in the sampling densities of $1 / 4,1 / 2,1,2$ and $4 \mathrm{ha}$, being the first density taken as a reference for comparison. The methods of comparison were the overall accuracy and Kappa index. The decrease in sample density depreciated the quality of the generated maps. All sampling densities differ as to the accuracy, however, showed good levels of accuracy for the sample density of one sample per hectare. Precision agriculture uses in a better way the amount of lime and fertilizer than conventional agriculture.
\end{abstract}

Key words: precision agriculture, Kappa, kriging 


\section{INTRODUÇÃO}

O conhecimento da variabilidade espacial dos atributos do solo, como os que constituem a fertilidade do solo, é o que envolve maiores custos e dificuldades com amostragem e análises (Fiorio \& Demattê, 2009) e entre os principais métodos para tal finalidade está a amostragem georreferenciada em malha (Ragagnin et al., 2010) sendo este método o mais eficiente para sua identificação.

Com a informação da posição geográfica de cada ponto na amostragem sistemática aliada ao resultado da análise de solo, pode-se conhecer a distribuição espacial dos atributos da fertilidade do solo utilizando-se técnicas de geoestatística e geoprocessamento com a geração de mapas temáticos que podem servir de auxílio a futuras correções do solo a taxas variáveis (Corá \& Beraldo, 2006) para as mais variadas culturas de grande importância, como a soja, considerada a leguminosa alimentar mais importante do mundo, situando-se o Brasil como segundo maior produtor mundial do grão (Passos et al., 2011).

A aplicação de fertilizantes e corretivos a taxas variáveis baseadas na agricultura de precisão (AP) apresenta grande alternativa para potencializar o processo produtivo e minimizar o impacto da atividade agrícola no meio ambiente (Oliveira et al., 2008). Weirich Neto et al. (2006) e Barbieri et al. (2008) demonstraram a maior eficiência na utilização de insumos na $\mathrm{AP}$, com maior nível de detalhamento em relação à agricultura convencional em que as amostras são retiradas de maneira aleatória e as recomendações são baseadas na média dos resultados encontrados.

Quanto maior o nível de detalhamento amostral dos atributos químicos do solo maior também a precisão dos mapas gerados representando mais fortemente a realidade encontrada a campo; no entanto, o custo e o trabalho com amostragens intensas podem ser fatores limitantes (Knob, 2006).

Em busca de economia e praticidade muitas vezes a amostragem é feita de tal forma que pode não representar as características reais do campo e densidades amostrais com uma amostra a cada cinco hectares são comumente feitas sem qualquer justificativa (Nanni et al., 2011).

Objetivou-se com este trabalho estabelecer uma densidade amostral que ofereça precisão nos mapas de atributos químicos gerados sobre diferentes densidades amostrais, em duas profundidades, e sua implicação prática na recomendação de adubação e calagem para a cultura da soja.

\section{Material e MÉTOdos}

O estudo foi realizado no município de Guarapuava, PR, na propriedade denominada Fazenda Cupim situada nas coordenadas $25^{\circ} 32^{\prime} 08^{\prime \prime} \mathrm{S}$ e $51^{\circ} 38^{\prime} 17^{\prime \prime} \mathrm{O}$. Na classificação de Koppen o clima local é do tipo Cfb cujas principais características são a falta de estação seca definida, média de temperatura inferior a $22{ }^{\circ} \mathrm{C}$ no mês mais quente e inferior a $18{ }^{\circ} \mathrm{C}$ no mês mais frio, com verões brandos e geadas severas, frequentes no inverno. A altitude local varia em torno de $1030 \mathrm{~m}$ e o solo do talhão estudado, com 48 ha é classificado, segundo suas características, como Latossolo Bruno.
A propriedade adota o plantio direto há mais de dez anos, sendo o milho, o trigo e a soja as principais culturas utilizadas. A área recebe adubação conforme a cultura implantada no momento e calagem periodicamente, ambas baseadas na média do resultado de análise de solo.

No talhão estudado a topografia do terreno é levemente ondulada, com declividade média em torno de $4-6 \%$ ao longo de toda a extensão; no entanto, em algumas porções do terreno a declividade pode chegar a $10-12 \%$ apresentando porções côncavas e convexas.

Para a coleta de amostras foram estabelecidas, de início, as grades amostrais com o auxílio de GPS, do AutoCAD ${ }^{\circledR}$ e do programa Track Maker Pro ${ }^{\circledR}$. Os dados de perímetro do talhão foram obtidos com GPS; posteriormente, os dados de perímetro foram transferidos para o computador através do programa TrackMaker Pro ${ }^{\circledR}$ e neste convertidos para formato DXF e na sequência importados para o AutoCAD ${ }^{\circledR}$ para estabelecimento das grades. Tanto o GPS quanto os programas utilizados foram padronizados para gerar dados no sistema de Coordenadas UTM, com Datum South America 1969 (SAD 69).

A Figura 1 mostra a área de estudo e os pontos de coleta de amostra, grades amostrais e coordenadas UTM.

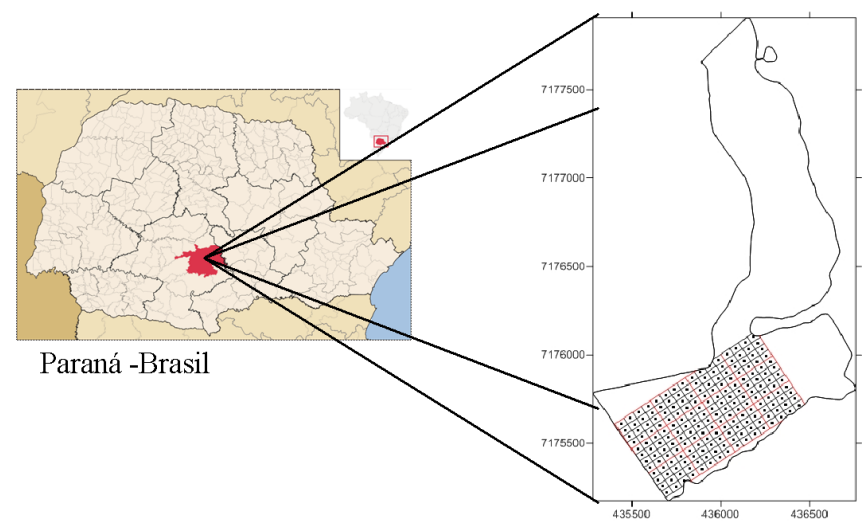

Figura 1. Localização da propriedade no Estado do Paraná, coordenadas e melhor posição de estabelecimento das grades e pontos dentro da área de estudo

No CAD o perímetro foi estudado quanto à melhor posição de estabelecimento das grades que foram elaboradas com a ferramenta OFFSET deste programa, gerando 192 unidades amostrais com área de $2500 \mathrm{~m}^{2}$ dispostas em 16 linhas e 12 colunas totalizando $48 \mathrm{ha}$, e de onde foram retiradas as amostras. No centro de cada quadrícula foi introduzido um ponto numerado com função de orientar o local da coleta das amostras.

Após estabelecidos as grades e os pontos no CAD, o arquivo foi salvo em formato DXF e aberto novamente pelo software Track Maker Pro ${ }^{\circledR}$ possibilitando transferir os novos dados para o GPS. As amostras foram coletadas e numeradas com orientação do GPS através da localização dos pontos no terreno.

A coleta de solo foi realizada no mês de dezembro do ano de 2010, após a colheita da cultura do trigo, com a utilização de trado tipo sonda, com 8 subamostras para formar uma amostra composta em cada grade, nas profundidades de 0-10 e 0-20 $\mathrm{cm}$. Segundo Santos et al. (2009) oito amostras simples para formar uma amostra composta são suficientes para representar 
uma unidade de amostragem. Das oito subamostras duas foram retiradas no centro da grade, ou seja, na localização do ponto e as outras seis retiradas duas a duas com distâncias equivalentes em um raio médio de oito metros a partir do centro, como mostra a Figura 2.

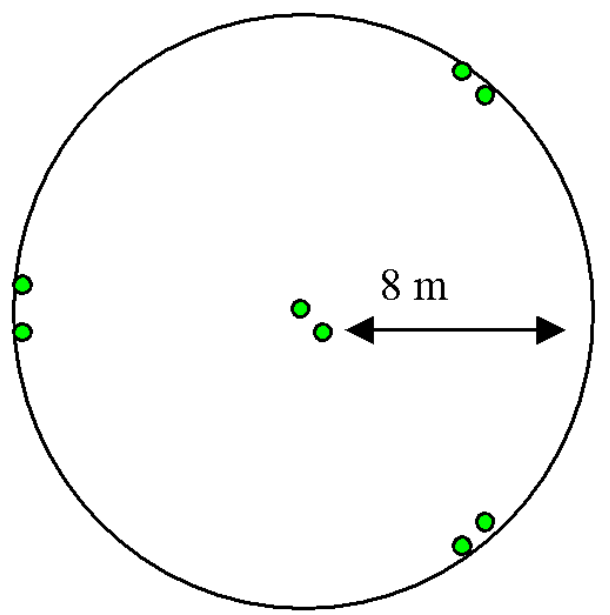

Figura 2. Esquema de amostragem de solo com oito subamostras para formar uma amostra composta

As amostras retiradas foram secadas, moídas e peneiradas em malha de $2 \mathrm{~mm}$ e posteriormente seguiram para análise química para quantificação dos teores de $\mathrm{P}, \mathrm{K}, \mathrm{Ca}, \mathrm{Mg}, \mathrm{H}+\mathrm{Al}$ e $\mathrm{pH}$ através dos quais foram calculadas a saturação de bases (V\%) e a necessidade de calagem (NC). A NC foi calculada para elevar a saturação de bases a 70\%.

As análises das amostras foram realizadas no Laboratório de Solos e Nutrição de Plantas da Universidade Estadual do Centro Oeste (UNICENTRO) conforme metodologia citada por Pavan et al. (1992) em que as seguintes técnicas foram utilizadas para quantificar os atributos: $\mathrm{pH}$ em $\mathrm{CaCl}_{2}$, na proporção de $1: 2,5 ; \mathrm{H}+$, por solução SMP; P e K, por Melihch-1; Ca e Mg, em KCl 1N.
Para gerar grades maiores as amostras foram retiradas de modo que uma amostra passasse a representar uma área onde anteriormente duas amostras a representavam; contudo, além da grade de $2500 \mathrm{~m}^{2}$ foram geradas outras com áreas de 5000 , 10000,20000 e $40000 \mathrm{~m}^{2}$, equivalentes a 1/4, 1/2,1,2 e 4 ha, respectivamente.

Os resultados das análises não foram vinculados às coordenadas, mas, sim, a valores que representam as distâncias entre os pontos amostrados dispostos em planos cartesianos, processo que facilita a elaboração e o estudo de dados dos mapas.

Os valores dos atributos encontrados para as diferentes grades vinculados às distâncias entre os pontos foram submetidos à estatística descritiva por meio do programa Assistat-Statistical (Silva \& Azevedo, 2009) e análise espacial por meio da geoestatística, através do programa GS+ (Robertson, 2008) o qual permite ajustar semivariogramas e modelos para krigagem e define a dependência espacial dos atributos e sua intensidade. Nos semivariogramas os modelos foram escolhidos com base na menor soma de quadrados de resíduos (SQR) e maior coeficiente de determinação $\left(\mathrm{R}^{2}\right)$. Utilizaram-se os modelos esférico e linear sem patamar (Tabela 1). Os modelos sem patamar não apresentam, em seus cálculos, o parâmetro C, possibilitando o processo de interpolação mesmo sem a presença do estabelecimento do limite de dependência espacial.

Após o ajuste de um modelo matemático aos semivariogramas dos atributos químicos do solo foram gerados os mapas de distribuição espacial pelo método da krigagem utilizando-se o programa Surfer (Golden software, 2010).

Os mapas gerados foram, na sequência, importados pelo programa Idrisi Taiga (Eastman, 2009) no qual foram atribuídas classes de isolinhas buscando englobar a amplitude total dos dados limitando-as ao máximo de 6 classes por atributo (Tabela 2).

Tabela 1. Parâmetros dos semivariogramas para os atributos da fertilidade química do solo nas diferentes densidades amostrais para as camadas de $0-10$ e $0-20 \mathrm{~cm}$

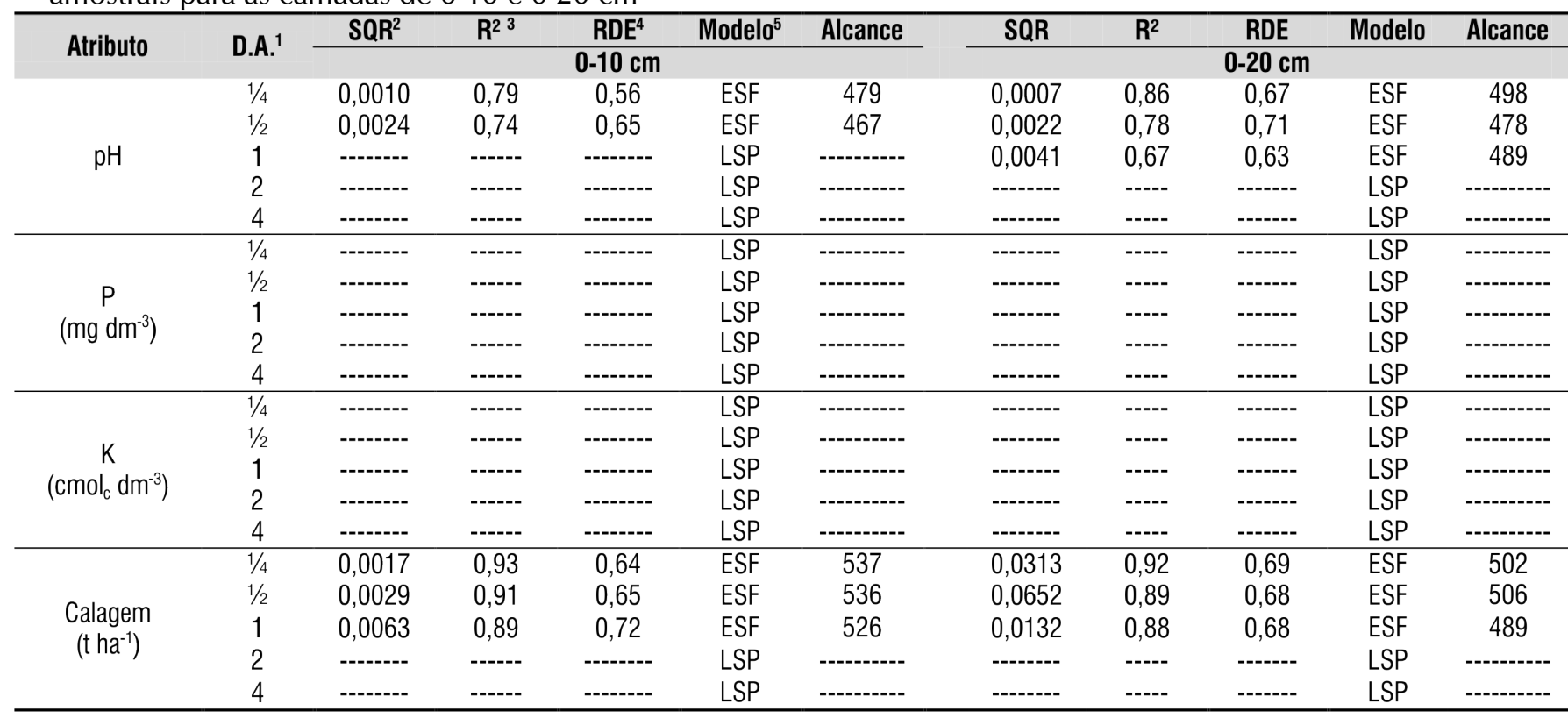

${ }^{1}$ D.A. - Densidade amostral; ${ }^{2}$ Soma do quadrado dos resíduos; ${ }^{3}$ Coeficiente de determinação; ${ }^{4}$ Razão de dependência espacial $(\mathrm{C} / \mathrm{C} 0+\mathrm{C}) ;{ }^{5} \mathrm{ESF}$ - esférico, LSP - linear sem patamar 
Tabela 2. Distribuição dos limites das classes para elaboração dos mapas de atributos químicos do solo por krigagem

\begin{tabular}{lccccccc}
\hline \multirow{2}{*}{ Atributos } & LI & LS & LS & LS & LS & LS & LS \\
\cline { 2 - 8 } & \multicolumn{7}{c}{ Classe } \\
\cline { 2 - 8 } & $\mathbf{1}$ & $\mathbf{1}$ & $\mathbf{2}$ & $\mathbf{3}$ & $\mathbf{4}$ & $\mathbf{5}$ & $\mathbf{6}$ \\
$\mathrm{H}+\mathrm{Al}\left(\mathrm{cmol}_{\mathrm{C}} \mathrm{dm}^{-3}\right)$ & 4,5 & 5,0 & 5,5 & 6,0 & 6,5 & 7,0 & \\
$\mathrm{P}\left(\mathrm{mg} \mathrm{dm}^{-3}\right)$ & 2 & 4 & 6 & 8 & & & \\
$\mathrm{~K}\left(\mathrm{cmol}_{\mathrm{c}} \mathrm{dm}^{-3}\right)$ & 0 & 3 & 6 & 9 & 12 & 15 & 18 \\
$\mathrm{Ca}\left(\mathrm{cmol}_{\mathrm{c}} \mathrm{dm}^{-3}\right)$ & 0 & 0,15 & 0,30 & 0,45 & 0,60 & 0,75 & 0,90 \\
$\mathrm{Mg}\left(\mathrm{cmol}_{\mathrm{c}} \mathrm{dm}^{-3}\right)$ & 2 & 4 & 6 & 8 & 10 & & \\
$\mathrm{~V}(\%)$ & 2 & 4 & 6 & 8 & & & \\
\hline
\end{tabular}

LI - Limite inferior da classe; LS - Limite superior da classe correspondente ao limite inferior da classe seguinte

Posterior ao estabelecimento das classes por meio da ferramenta TABCROSS do IDRISI TAIGA, os mapas de densidades amostrais menores foram comparados com o de maior densidade correspondente a $1 / 4$ ha.

O cruzamento dos mapas dois a dois gera uma matriz de erro ou matriz de confusão que expressa a relação entre os pixels originais (expressos na maior densidade amostral que mais se correlaciona com a realidade) e classificados (densidades amostrais menores) (Coelho \& Giasson, 2010) possibilitando encontrar a exatidão global, que expressa todas as coincidências de pixels de mesma classe em diferentes mapas e o índice Kappa (Cohen, 1960) o qual mede a confiabilidade da exatidão entre dois mapas através da Eq. 1.

$$
\mathrm{K}=\frac{\mathrm{Po}+\mathrm{Pc}}{1-\mathrm{Pc}}
$$

em que:

K - Estimativa do índice Kappa

Po - Proporção de observações corretamente classificadas ou exatidão global

Pc - Proporção esperada de acerto ao acaso

As variâncias do índice Kappa são dadas através da Eq. 2.

$$
\sigma^{2}(\mathrm{~K})=\frac{\mathrm{Po}(1-\mathrm{Po})}{\mathrm{N}(1-\mathrm{Pc})^{2}}
$$

em que:

$\sigma^{2} \quad$ - Variância do Índice Kappa

$\mathrm{N}$ - número total de pixels contemplados pela matriz de erros

Os índices Kappa foram comparados pelo teste Z com 95\% de significância pela Eq. 3.

$$
\mathrm{Z}_{\text {calc }}=\frac{\mathrm{K}_{1}-\mathrm{K}_{2}}{\left(\sqrt{\sigma_{1}^{2}+\sigma_{2}^{2}}\right)}
$$

$\mathrm{O}$ valor de $\mathrm{Z}_{\text {calc }}$ encontrado que ultrapassar o valor de $\mathrm{Z}$ tabelado que para a significância de $95 \%$ equivale a 1,96 , reflete a inexistência da igualdade estatística entre os índices Kappa, diferenciando-os significativamente entre si.
Para quantificação das necessidades totais de adubação e calagem para a cultura da soja nas diferentes densidades amostrais e profundidades, foram utilizados parâmetros de fertilidade propostos por EMBRAPA (2010) (Tabela $3)$ e a recomendação de calagem foi feita pelo método de saturação de bases no intuito de elevar V a 70\%. Os mapas das recomendações foram criados e quantificados com o uso dos programas Surfer e IDRISI Taiga.

Tabela 3. Recomendação de adubação com P e K para

\begin{tabular}{|c|c|c|c|}
\hline \multicolumn{2}{|c|}{ Análise de solo } & \multicolumn{2}{|c|}{ Quantidade a aplicar } \\
\hline \multirow{2}{*}{$\begin{array}{c}P \\
\mathrm{mg} \mathrm{dm^{-3 }}\end{array}$} & \multirow{2}{*}{$\begin{array}{c}\mathrm{K} \\
\mathrm{cmol}_{\mathrm{c}} \mathrm{dm}^{-3}\end{array}$} & $\mathrm{P}_{2} \mathrm{O}_{5}$ & $\mathrm{~K}_{2} \mathrm{O}$ \\
\hline & & \multicolumn{2}{|c|}{$\mathrm{kg} \mathrm{ha}^{-1}$} \\
\hline \multirow{4}{*}{$<3,0$} & $<0,10$ & 100 & 90 \\
\hline & 0,10 a 0,20 & 100 & 70 \\
\hline & 0,20 a 0,30 & 100 & 50 \\
\hline & $>0,30$ & 100 & 40 \\
\hline \multirow{4}{*}{3,0 a 6,0} & $<0,10$ & 80 & 90 \\
\hline & 0,10 a 0,20 & 80 & 70 \\
\hline & 0,20 a 0,30 & 80 & 50 \\
\hline & $>0,30$ & 80 & 40 \\
\hline \multirow{4}{*}{$>6,0$} & $<0,10$ & 60 & 90 \\
\hline & 0,10 a 0,20 & 60 & 70 \\
\hline & 0,20 a 0,30 & 60 & 50 \\
\hline & $>0,30$ & 60 & 40 \\
\hline
\end{tabular}
a cultura da soja no estado do Paraná em solos com teor de argila superior a $40 \%$

Fonte: Adaptado da EMBRAPA (2010)

As recomendações feitas quanto ao aspecto de agricultura de precisão foram comparadas com as recomendações feitas com base na agricultura tradicional cuja média total é utilizada para tal indicação. Esta comparação foi realizada verificandose a porcentagem do mapa gerado para agricultura de precisão que é ocupada pela classe na qual a média total está inserida.

\section{Resultados E Discussão}

Para todos os atributos as densidades amostrais maiores apresentam maior número de classes e à medida em que a densidade amostral decresce, as classes mais extremas perdem representação ou mesmo desaparecem para incrementar as classes mais próximas àquela na qual a média está inserida. Esta característica pode ser observada na Tabela 4 cuja distribuição de frequência encontrada para o atributo $\mathrm{pH}$, na profundidade 0-10 cm, representa o mesmo comportamento para os demais atributos estudados e esclarece a relação entre a diminuição da densidade amostral e a perda de classes ou diminuição dos valores de algumas classes, ou seja, a redução do detalhamento.

Tabela 4. Distribuição de frequência do pH em mapas

\begin{tabular}{|c|c|c|c|c|c|c|c|}
\hline \multirow{2}{*}{$\mathrm{pH}$} & \multirow{2}{*}{$\mathbf{L I}^{(1)}$} & \multirow{2}{*}{$\mathbf{L S}^{(2)}$} & $1 / 4^{(3)}$ & $1 / 2^{(3)}$ & $1^{(3)}$ & $2^{(3)}$ & $4^{(3)}$ \\
\hline & & & \multicolumn{5}{|c|}{$\%$} \\
\hline Classe 1 & 4,5 & 5,0 & 0,04 & 0,23 & 1,63 & 1,81 & 0,40 \\
\hline Classe 2 & 5,0 & 5,5 & 28,77 & 22,67 & 14,77 & 31,33 & 30,50 \\
\hline Classe 3 & 5,5 & 6,0 & 58,42 & 62,31 & 71,60 & 61,21 & 69,06 \\
\hline Classe 4 & 6,0 & 6,5 & 12,31 & 14,21 & 10,90 & 5,65 & 0,04 \\
\hline Classe 5 & 6,5 & 7,0 & 0,46 & 0,58 & 1,10 & 0 & 0 \\
\hline
\end{tabular}
de krigagem sob diferentes intensidades amostrais na profundidade de $0-10 \mathrm{~cm}$ 
O conhecimento detalhado da propriedade, primado pela agricultura de precisão, sofre depreciação com a redução dos valores e classes que representam justamente as porções do terreno que merecem atenção especial. A Figura 3 demonstra este comportamento para o $\mathrm{pH}$ que se assemelhasse a todos os demais atributos.

Nos mapas (Figura 3) é possível observar que classes que ocupam porções menores do terreno são envolvidas por classes mais abundantes e deixam de existir perdendo representatividade sempre que a densidade amostral diminui, comportamento observado em todos os atributos.

Valores de exatidão global que demonstram as reais coincidências entre as mesmas classes em diferentes mapas são também índices que apresentam a queda de precisão com a redução da densidade amostral e podem ser observados naTabela 5.

É possível observar (Tabela 5) o decréscimo da exatidão global à medida em que a densidade amostral reduz; na profundidade de $0-10 \mathrm{~cm}$, a média geral de exatidão para a densidade de uma amostra a cada $1 / 2$ ha é de $82,1 \%$, variando de 75,4 até $88,3 \%$, passando para a média $69,8 \%$ na densidade de uma amostra por hectare e para $62,6 \%$ quando uma amostra a cada 2 ha chegando, enfim, à média de $56,2 \%$ na menor densidade equivalente a 1 amostra a cada 4 ha, com variação de 47,3 até $65,8 \%$.

Na profundidade de $0-20 \mathrm{~cm}$ (Tabela 5) os índices são semelhantes aos da profundidade $0-10 \mathrm{~cm}$ e apresentam valores de exatidão global médios próximos e pouco superiores.

Com a redução dos índices de exatidão global (Tabela 5) ocorre um aumento nos índices de valores subestimados e superestimados, valores tais que originam os erros nas atividades de adubação e calagem acarretando tanto aplicações em quantidades insuficientes quanto super dosagens em determinadas áreas do terreno.

Os índices Kappa, encontrados e expressos na Tabela 6 , demonstram a real fidedignidade entre diferentes mapas excluindo os valores de acerto ao acaso encontrados no coeficiente de exatidão global (Renó et al., 2011) explicando os valores inferiores deste índice para todos os atributos em relação ao coeficiente de exatidão global, observados na Tabela 5 .

Todas as densidades amostrais diferiram entre si para todos os atributos estudados em ambas as profundidades, evidenciando que dentre os detalhamentos propostos no trabalho não foram encontradas uma estabilização dos resultados nem estabilização da precisão com a diminuição da densidade amostral nem, ainda, estabilização da densidade amostral com aumento do detalhamento amostral.

A estabilização da precisão com a diminuição da densidade amostral baixa a qualidade de exatidão dos mapas a níveis não desejados na agricultura de precisão. Por outro lado, a estabilização da densidade amostral, na qual o aumento da mesma não acarretaria grandes ganhos em precisão, poderia inviabilizar o processo de amostragem pelo intenso trabalho de coleta e custo com análises aumentando a relação custo benefício.

Para as duas profundidades os níveis médios de exatidão, conforme os índices Kappa expressos na Tabela 6, revelam que os mapas gerados sobre a densidade amostral de 1 amostra a cada $1 / 2$ ha apresentam qualidade muito boa para os atributos
A.

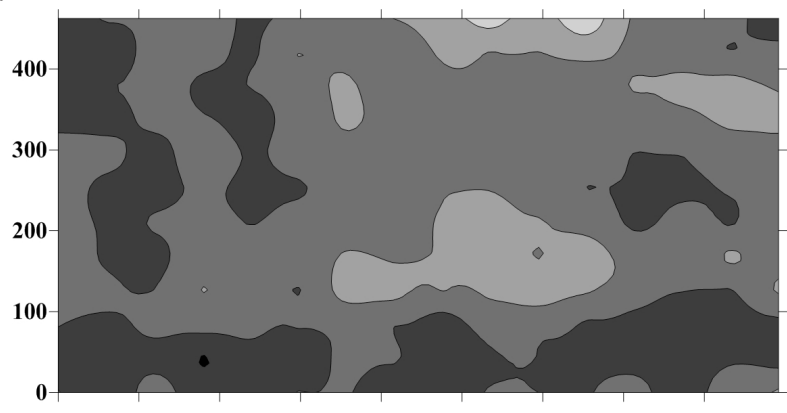

B.

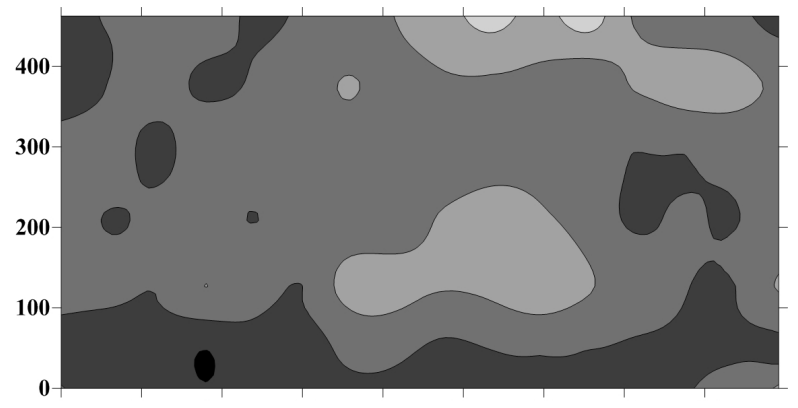

C.

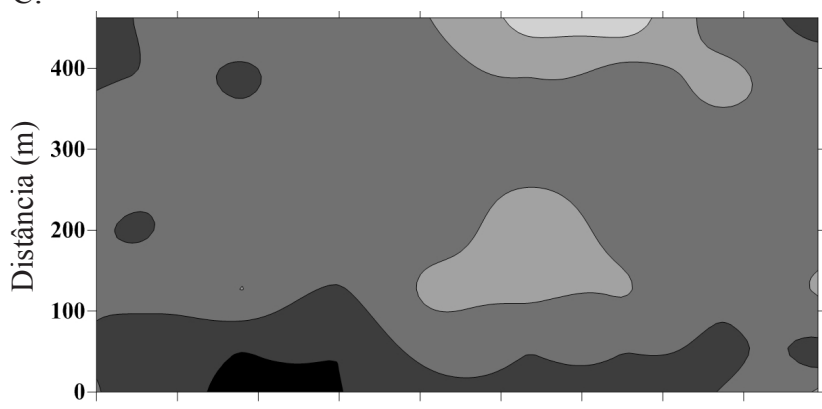

D.

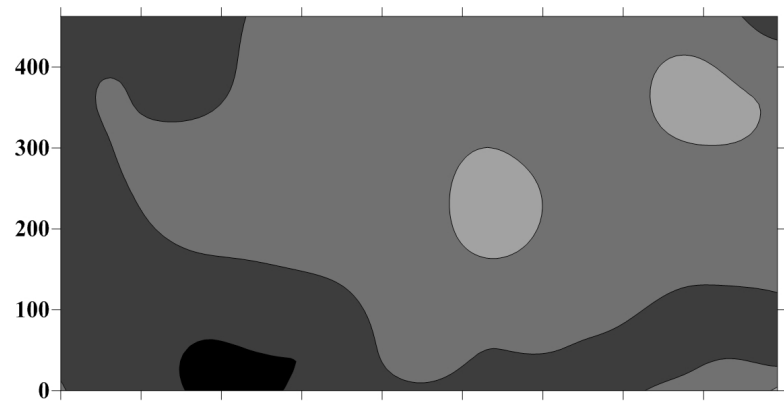

E.

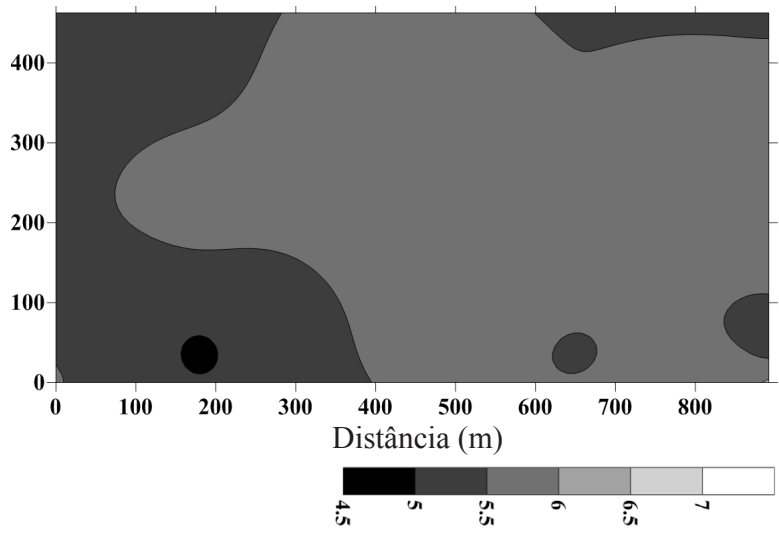

Figura 3. Mapa de krigagem do atributo $\mathrm{pH}$ na profundidade $0-10 \mathrm{~cm}$ obtido nas densidades amostrais de $1 / 4$ ha (A), 1/2 ha (B), 1 ha (C), 2 ha (D) e 4 ha (E) 
Tabela 5. Índice de exatidão global dos atributos de um Latossolo Bruno, comparadas as diferentes densidades amostrais com a densidade de uma amostra a cada $1 / 4$ ha, nas profundidades de $0-10 \mathrm{~cm}$ e $0-20 \mathrm{~cm}$

\begin{tabular}{|c|c|c|c|c|c|c|c|c|c|c|c|c|}
\hline \multirow{3}{*}{ Atrib } & \multicolumn{3}{|c|}{$1 / 2$ ha } & \multicolumn{3}{|c|}{1 ha } & \multicolumn{3}{|c|}{2 ha } & \multicolumn{3}{|c|}{4 ha } \\
\hline & Sub $^{1}$ & Acrt $^{2}$ & Sup ${ }^{3}$ & Sub & Acrt & Sup & Sub & Acrt & Sup & Sub & Acrt & Sup \\
\hline & \multicolumn{12}{|c|}{$\%$} \\
\hline & \multicolumn{12}{|c|}{$0-10 \mathrm{~cm}$} \\
\hline $\mathrm{H}+\mathrm{Al}$ & 7,7 & 88,3 & 4,0 & 8,9 & 80,6 & 10,4 & 8,1 & 70,8 & 21,1 & 7,5 & 64,8 & 27,7 \\
\hline $\mathrm{P}$ & 6,4 & 80,7 & 13,0 & 12,6 & 58,3 & 29,1 & 9,6 & 49,5 & 40,8 & 16,1 & 51,1 & 32,8 \\
\hline K & 7,1 & 86,0 & 7,0 & 12,2 & 74,7 & 13,2 & 15,0 & 73,4 & 11,6 & 17,8 & 65,8 & 16,3 \\
\hline V & 6,8 & 83,6 & 9,7 & 11,7 & 71,4 & 17,0 & 23,3 & 64,6 & 12,0 & 34,3 & 47,3 & 18,4 \\
\hline \multirow[t]{2}{*}{ Média } & 7,7 & 82,1 & 10,2 & 11,8 & 69,8 & 18,4 & 17,9 & 62,6 & 19,5 & 22,5 & 56,2 & 21,3 \\
\hline & \multicolumn{12}{|c|}{$0-20 \mathrm{~cm}$} \\
\hline $\mathrm{pH}$ & 5,4 & 88,3 & 11,6 & 8,2 & 72,7 & 19,1 & 18,9 & 68,3 & 12,8 & 34,6 & 61,6 & 3,8 \\
\hline $\mathrm{H}+\mathrm{Al}$ & 5,9 & 89,3 & 4,8 & 6,2 & 84,5 & 9,3 & 5,4 & 77,1 & 17,5 & 4,8 & 74,7 & 20,5 \\
\hline $\mathrm{P}$ & 6,6 & 81,6 & 11,8 & 10,1 & 61,6 & 28,3 & 7,7 & 54,9 & 37,4 & 14,7 & 60,2 & 25,2 \\
\hline Média & 5,3 & 87,0 & 8,5 & 8,3 & 76,9 & 14,8 & 12,8 & 70,9 & 16,3 & 20,3 & 67,9 & 11,8 \\
\hline
\end{tabular}

${ }^{1}$ Valores subestimados; ${ }^{2}$ Valores de exatidão global; ${ }^{3}$ Valores superestimados

Tabela 6. Índice Kappa dos mapas de diferentes densidades amostrais comparados com o mapa de densidade amostral de 1 amostra a cada $1 / 4$ ha

\begin{tabular}{|c|c|c|c|c|c|}
\hline Atributo & $1 / 4$ ha & $1 / 2$ ha & $\begin{array}{c}1 \text { ha } \\
\%\end{array}$ & 2 ha & 4 ha \\
\hline $\begin{array}{l}\mathrm{pH} \\
\mathrm{H}+\mathrm{Al} \\
\mathrm{P} \\
\mathrm{K} \\
\mathrm{Ca} \\
\mathrm{Mg} \\
\mathrm{V} \\
\text { Média }\end{array}$ & $\begin{array}{l}100 a^{\star} \\
100 a \\
100 a \\
100 a \\
100 a \\
100 a \\
100 a \\
100\end{array}$ & $\begin{array}{l}64,54 \text { b } \\
72,44 \text { b } \\
69,76 \text { b } \\
72,07 \text { b } \\
58,44 \text { b } \\
64,54 \text { b } \\
69,46 \text { b } \\
67,32\end{array}$ & $\begin{array}{l}0-10 \mathrm{~cm} \\
42,97 \mathrm{c} \\
55,87 \mathrm{c} \\
35,04 \mathrm{c} \\
49,60 \mathrm{c} \\
38,24 \mathrm{c} \\
42,97 \mathrm{c} \\
48,76 \mathrm{c} \\
44,78\end{array}$ & $\begin{array}{l}30,24 d \\
27,27 d \\
25,22 d \\
47,00 d \\
27,79 d \\
30,24 d \\
38,19 d \\
32,28\end{array}$ & $\begin{array}{l}17,07 \mathrm{e} \\
02,02 \mathrm{e} \\
16,22 \mathrm{e} \\
31,85 \mathrm{e} \\
13,57 \mathrm{e} \\
17,07 \mathrm{e} \\
19,19 \mathrm{e} \\
16,71\end{array}$ \\
\hline $\begin{array}{l}\mathrm{pH} \\
\mathrm{H}+\mathrm{Al} \\
\mathrm{P} \\
\mathrm{K} \\
\mathrm{Ca} \\
\mathrm{Mg} \\
\mathrm{V} \\
\text { Média }\end{array}$ & $\begin{array}{l}100 a \\
100 a \\
100 a \\
100 a \\
100 a \\
100 a \\
100 a \\
100\end{array}$ & $\begin{array}{l}69,43 \text { b } \\
71,67 \text { b } \\
68,30 \text { b } \\
73,92 \text { b } \\
60,28 \text { b } \\
69,43 \text { b } \\
71,14 \text { b } \\
69,17\end{array}$ & $\begin{array}{l}0-20 \mathrm{~cm} \\
51,76 \mathrm{c} \\
58,50 \mathrm{c} \\
30,10 \mathrm{c} \\
61,58 \mathrm{c} \\
31,56 \mathrm{c} \\
51,76 \mathrm{c} \\
48,58 \mathrm{c} \\
47,69\end{array}$ & $\begin{array}{l}41,97 d \\
34,81 d \\
21,27 d \\
34,10 d \\
21,93 d \\
41,97 d \\
31,23 d \\
32,47\end{array}$ & $\begin{array}{l}23,13 \text { e } \\
19,51 \text { e } \\
13,42 \text { e } \\
23,60 \text { e } \\
10,46 \text { e } \\
23,13 \text { e } \\
22,59 \text { e } \\
19,41\end{array}$ \\
\hline
\end{tabular}

* Valores seguidos de letras diferentes, na linha, diferem estatisticamente pelo teste Z com $95 \%$ de significância, sendo a letra "a" atribuída à densidade amostral de referência correspondente a 1 amostra a cada $1 / 4$ ha

químicos estudados, conforme classificação proposta por Landis $\&$ Coch (1977). Na Tabela 7 é possível observar a qualidade de exatidão conforme o índice Kappa.

$\mathrm{Na}$ densidade amostral de uma amostra a cada 1 ha os atributos apresentaram boa qualidade de exatidão em relação aos mapas gerados com a maior densidade amostral.

As demais densidades amostrais que compreendem uma amostra a cada 2 e 4 ha apresentaram qualidade de razoável a ruim sendo então ineficiente para utilização em agricultura de precisão que preza justamente a qualidade de representação das características encontradas a campo.

Pressupondo que uma densidade amostral maior corresponde mais fortemente à realidade encontrada a campo e que são
Tabela 7. Nível de exatidão de uma classificação, conforme o valor de índice Kappa

\begin{tabular}{cccc}
\hline Índice Kappa (K) & Qualidade & $\mathbf{0 - 1 0} \mathbf{~ c m}$ & $\mathbf{0 - 2 0} \mathbf{~ c m}$ \\
\cline { 3 - 4 }$K \leq 20 \%$ & Ruim & 4 & ha \\
$20 \%<K<40 \%$ & Razoável & 2 & 2 \\
$40 \%<K<60 \%$ & Boa & 1 & 1 \\
$60 \%<K<80 \%$ & Muito Boa & $1 / 2$ & $1 / 2$ \\
$80 \% \leq K$ & Excelente & $1 / 4$ & $1 / 4$ \\
\hline
\end{tabular}

Fonte: Adaptado de Landis \& Koch (1977)

necessários mapas de dados que apresentem no mínimo boa qualidade de exatidão para sua utilização é possível atrelar à densidade amostral de uma amostra por hectare, a suficiência de qualidade para uso na agricultura de precisão.

Neste caso, onde os índices Kappa indicam boa qualidade de exatidão não significa que a precisão será limitada a 40 a $60 \%$ e, sim, essas porcentagens serão o limite mínimo de precisão. Os valores de acerto ao acaso, desconsiderados pelo índice Kappa (Tabela 7) não deixarão de ser acertos em um processo de correção do solo, elevando a precisão (considerando acertos reais e casuais) à média $69,8 \%$ na profundidade $0-10$ $\mathrm{cm}$ e $76,9 \%$ na profundidade $0-20 \mathrm{~cm}$, conforme os índices de exatidão global (Tabela 6).

Para elevação da saturação de bases a 70\% recomendação dada segundo EMBRAPA (2010) para a cultura da soja, utilizando-se a média dos resultados das análises, seria necessário $0,14 \mathrm{Mg} \mathrm{ha}^{-1}$ de corretivo com PRNT 100\% na profundidade $0-10 \mathrm{~cm}$ e $0,86 \mathrm{Mg} \mathrm{ha}^{-1}$ na profundidade 0-20 $\mathrm{cm}$ totalizando, em seus $48 \mathrm{ha}$, uma necessidade de calagem de 6,72 $\mathrm{Mg}$ e 41,28 Mg respectivamente, para 0-10 e $0-20 \mathrm{~cm}$. No entanto, essas necessidades foram aumentadas consideravelmente por ocasião da distribuição diferenciada proporcionada pela agricultura de precisão como é possível observar na Tabela 8 .

Nas duas profundidades, quando comparadas as necessidades de calagem utilizando o método baseado na agricultura de 
Tabela 8. Necessidade de calagem em Latossolo Bruno sob plantio direto na região de Guarapuava, PR, em diferentes densidades amostrais para uma área de 48 ha, em duas profundidades

\begin{tabular}{ccc}
\hline Densidade & Necessidade de calagem (PRNT 100\%) - Mg \\
\cline { 2 - 3 } Amostral (ha) & $\mathbf{0 - 1 0} \mathbf{~ c m}$ & $\mathbf{0 - 2 0} \mathbf{~ c m}$ \\
$1 / 4$ & 18,0 & 57,30 \\
$1 / 2$ & 17,5 & 55,60 \\
1 & 17,2 & 54,50 \\
2 & 21,0 & 63,80 \\
4 & 21,5 & 71,00 \\
48 & 6,72 & 41,28 \\
\hline
\end{tabular}

precisão e o método convencional baseado na média, as diferenças de NC são de tais grandezas (Tabela 8) pelo fato do primeiro método não incluir as áreas com saturação de base superior a $70 \%$, que não receberiam calagem, e áreas com saturação menores a receberiam proporcionalmente à sua redução mas quando é a média total que serve como base de cálculo, as amostras com $\mathrm{V}$ superior a $70 \%$ reduziriam a $\mathrm{NC}$ referida acarretando em diminuição da quantidade total de corretivos.

O comportamento de aumento da NC pelo uso da agricultura de precisão (AP) no local de estudo é resultado da alta fertilidade deste solo, com grande parte dos resultados obtidos com o detalhamento alcançado com a amostragem georreferenciada demonstrando valores de saturação de bases superiores a $70 \%$, reduzindo a necessidade de calagem pelo uso da média. Weirich Neto et al. (2006) encontraram resultados semelhantes na cultura do milho concluindo pela necessidade de uma aplicação com 7,84 Mg maior de corretivo em AP do que na AC numa área de 9,6 ha; contudo, Menegatti et al. (2005) encontraram redução de $35 \%$ no uso de corretivo com utilização da AP em cultivo de cana-de-açúcar evidenciando haver discrepâncias com a alteração das exigências nutricionais das culturas e condições de solo.

Nos mapas apresentados nas Figuras 4 e 5 é possível observar as diferenças das $\mathrm{NC}$ em cada porção do terreno nas diferentes densidades amostrais e na média.

Da mesma forma que a calagem a necessidade de adubação foi superior para $\mathrm{AP}$ em relação à $\mathrm{AC}$, com exceção da adubação fosfatada na profundidade $0-20 \mathrm{~cm}$. Na Tabela 9 é possível observar as necessidades totais de fertilizantes nas diferentes densidades amostrais, profundidades e tipos de manejo (AP x $\mathrm{AC})$.

A alta fertilidade química do solo elevou a média dos níveis de $\mathrm{P}$ na profundidade $0-10 \mathrm{~cm}$, e de $\mathrm{K}$, nas profundidades 0-10 e 0-20 cm, a valores superiores a mais elevada classe de recomendação para adubação da soja correspondentes a $6 \mathrm{mg}$ $\mathrm{dm}^{-3}$ e $0,3 \mathrm{cmol}_{\mathrm{c}} \mathrm{dm}^{-3}$ respectivamente. Com isto, o uso desta alta média para fazer as recomendações acarretaria na mínima adubação necessária para a área total referente a $40 \mathrm{~kg}$ de $\mathrm{K}_{2} \mathrm{O}$ e $60 \mathrm{~kg}$ de $\mathrm{P}_{2} \mathrm{O}_{5}$ por hectare. Com o detalhamento da propriedade ocasionado pela coleta georreferenciada de amostras no terreno, aparecem porções nas quais é possível observar (Figuras 6 e 7) níveis mais baixos de fertilidade o que acarretaria em uma adubação maior nesses locais e, em consequência, maiores quantidades totais de fertilizantes quando comparadas com a utilização da média.
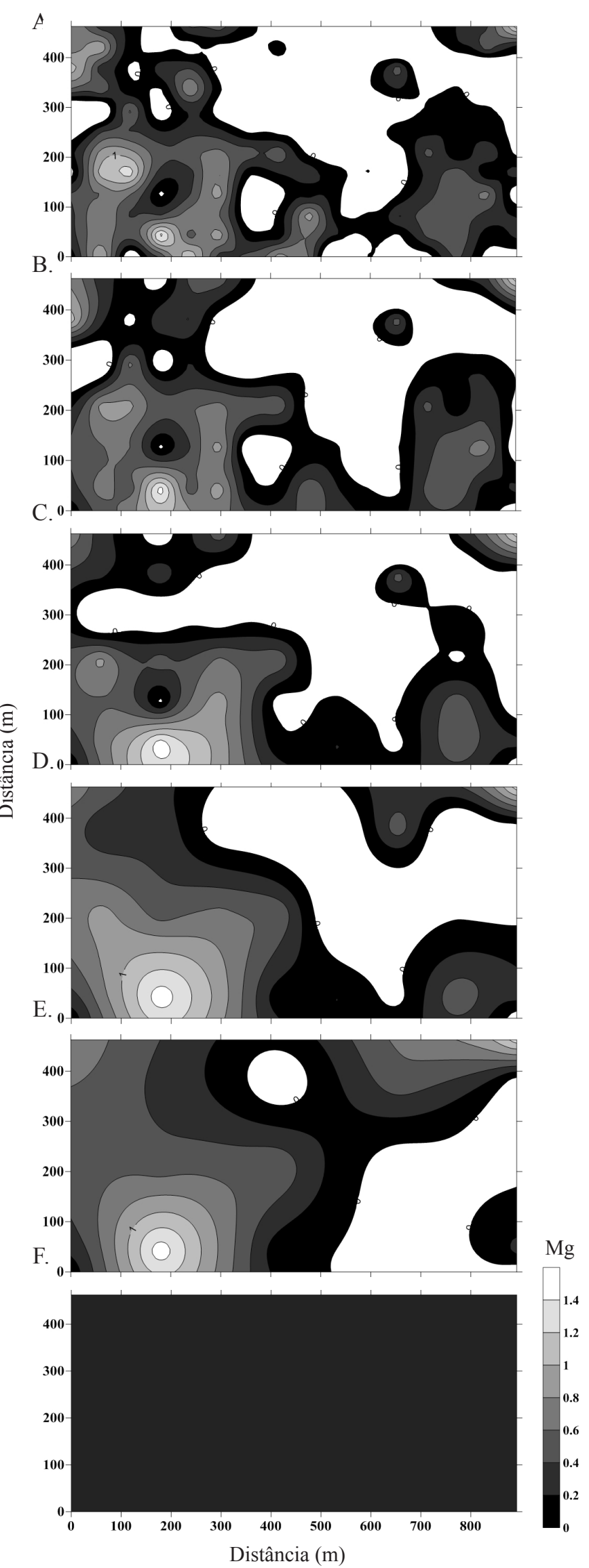

Figura 4. Mapas de necessidade de calagem (NC) na camada $0-10 \mathrm{~cm}$, nas densidades amostrais de $1 / 4$ ha $(A), 1 / 2$ ha $(B), 1$ ha $(C), 2$ ha (D), 4 ha (E) e 48 ha (F) 


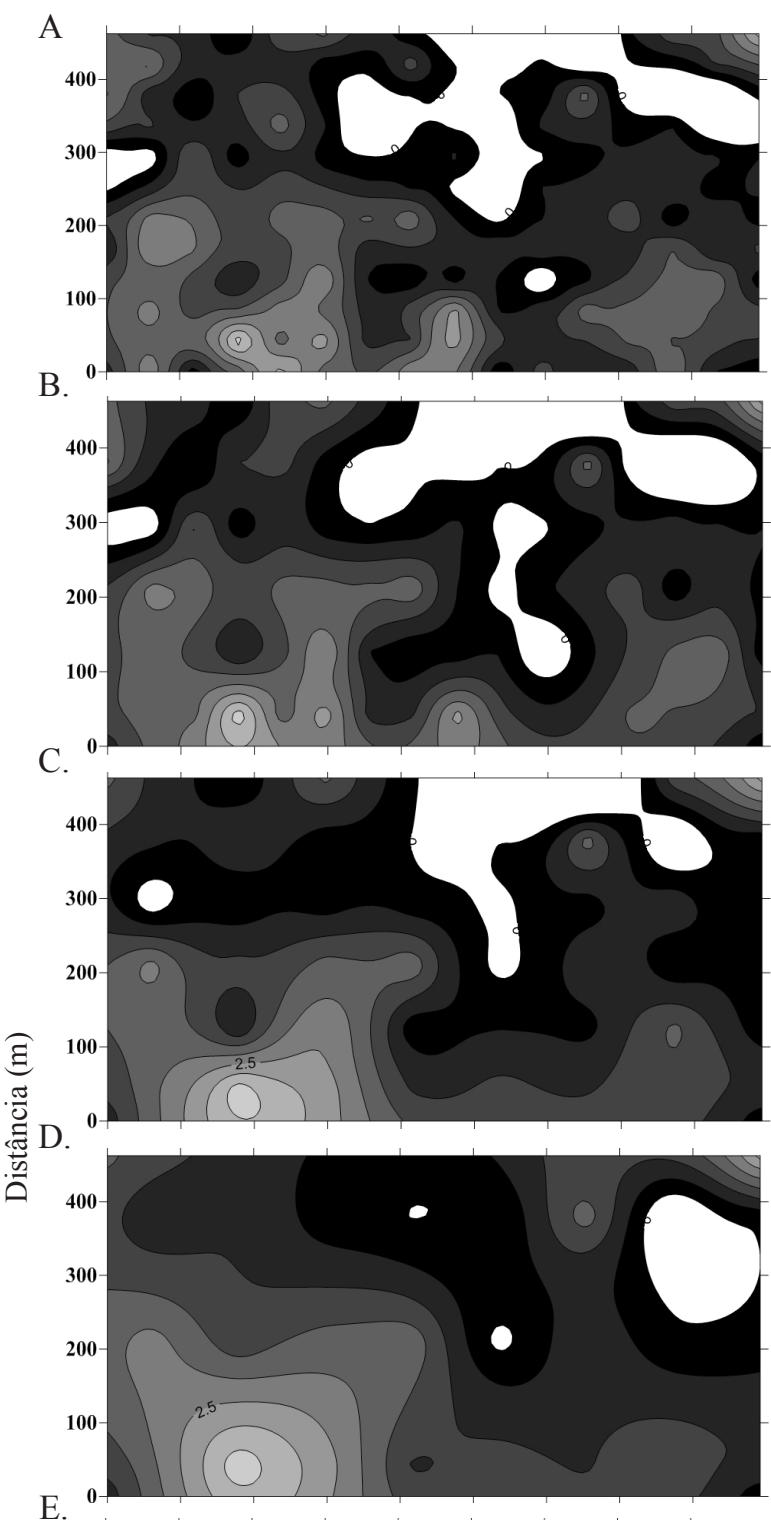

E.

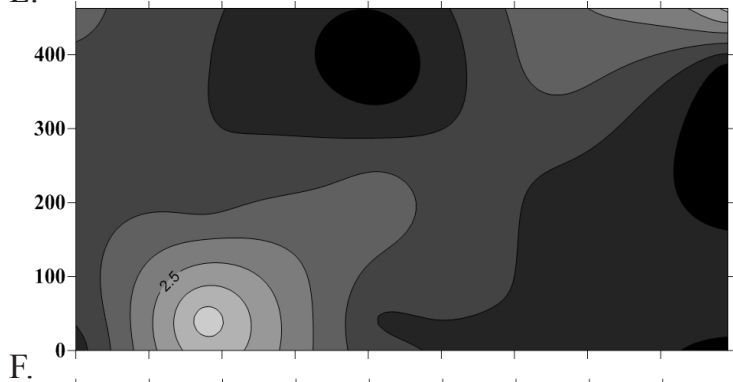

F.

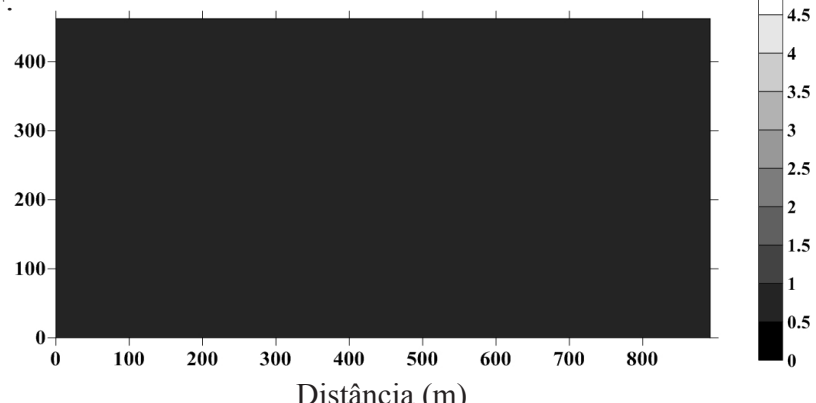

Figura 5. Mapas de necessidade de calagem (NC) na camada 0-20 cm, nas densidades amostrais de $1 / 4$ ha (A), $1 / 2$ ha (B), 1 ha (C), 2 ha (D), 4 ha (E) e 48 ha (F)
$\mathrm{O}$ atributo $\mathrm{P}$ apresentou, na profundidade $0-20 \mathrm{~cm}$, comportamento diferente estando seu teor médio presente na classe intermediária dos níveis de recomendação, expressos na Tabela 9. Com o uso de agricultura de precisão porções do terreno receberiam a mesma recomendação de adubação atribuída pelo uso do método convencional, outras porções receberiam quantidades superiores de fertilizantes e outras receberiam quantidades inferiores (Figura 6) caso em que o uso da AP reduziria a quantidade de fertilizantes totais, além desses serem colocados em locais de real necessidade.

Tabela 9. Necessidade total de $\mathrm{P}_{2} \mathrm{O}_{5}$ e $\mathrm{K}_{2} \mathrm{O}$ em uma área de $48 \mathrm{ha}$ em diferentes densidades amostrais

\begin{tabular}{|c|c|c|c|c|c|}
\hline \multirow{3}{*}{\multicolumn{2}{|c|}{$\begin{array}{l}\text { Amostra/ } \\
\text { Área (ha) }\end{array}$}} & \multicolumn{2}{|c|}{$\mathrm{P}_{2} \mathrm{O}_{5}(\mathrm{~kg})$} & \multicolumn{2}{|c|}{$\mathrm{K}_{2} \mathrm{O}(\mathrm{kg})$} \\
\hline & & $0-10$ & $0-20$ & $0-10$ & $0-20$ \\
\hline & & \multicolumn{4}{|c|}{ cm } \\
\hline \multirow{5}{*}{ AP } & $1 / 4$ & 3300 & 3783 & 1938 & 2080 \\
\hline & $1 / 2$ & 3352 & 3763 & 1929 & 2047 \\
\hline & 1 & 3300 & 3753 & 1925 & 1990 \\
\hline & 2 & 3285 & 3684 & 1923 & 1954 \\
\hline & 4 & 3351 & 3784 & 1926 & 2037 \\
\hline $\mathrm{AC}$ & 48 & 2880 & 3840 & 1920 & 1920 \\
\hline
\end{tabular}

AP - Agricultura de previsão; AC - Agricultura convencional

A provável diferença entre os níveis de $\mathrm{P}$ nas profundidades 0-10 e 0-20 cm está na forma com que este é depositado ao solo, associado ao sistema de manejo (PD) e à baixa mobilidade do elemento no perfil.

Os mapas apresentados nas Figuras 6 e 7 demonstram as classes que receberiam diferentes adubações com o uso da AP em diferentes densidades amostrais e pela média total.

Diferenças ocasionadas pela utilização da AP comparada com a AC também foram encontradas por Weirich Neto et al. (2006) na cultura do milho constatando que com o uso da segunda deixar-se-ia de aplicar $138,9 \mathrm{~kg}$ de $\mathrm{K}_{2} \mathrm{O}$ e se aplicariam $175 \mathrm{~kg}$ de $\mathrm{P}_{2} \mathrm{O}_{5}$ a mais do que o necessário, em uma área de 9,6 ha em termos gerais desconsiderando-se ainda as subdosagens e as superdosagens.

Barbieri et al. (2008) observaram, estudando a necessidade de aplicação de insumos em áreas côncavas e convexas comparando métodos de agricultura de precisão com métodos tradicionais, a maior eficiência do primeiro na aplicação de calcário, fósforo e potássio.

Oliveira et al. (2008) encontraram, estudando diferentes tipos de amostragem para geração de dados de recomendação de correção de fertilidade em café, zonas de déficit e excesso de adubação e calagem na área quando utilizaram amostras georreferenciadas e geoestatística e ressaltaram a impossibilidade de se encontrar essas diferentes zonas utilizando-se do método aleatório de amostragem (ziguezague).

Ferraz et al. (2011) verificaram, comparando a adubação feita com base em agricultura de precisão com a adubação feita com base no método convencional, a viabilidade econômica do primeiro em lavouras de café, principalmente em grandes áreas.

A alta fertilidade química no solo estudado que apresenta saturação de base mais elevada que $70 \%$ e média dos níveis de $\mathrm{P}$ (na profundidade $0-10 \mathrm{~cm}$ ) e $\mathrm{K}$ superiores às classes mais altas indicadas na recomendação de adubação, fez com que as quantidades totais de corretivos e fertilizantes aumentassem 
A.

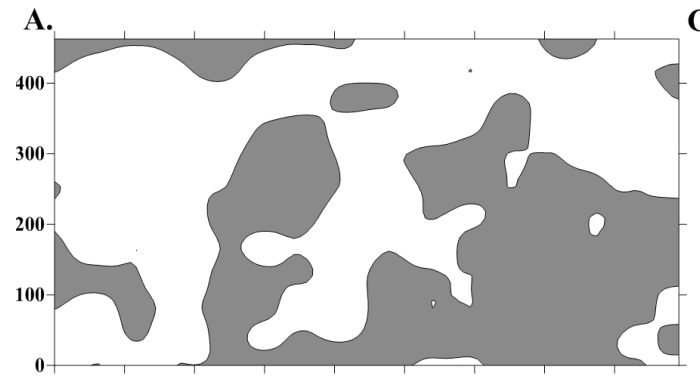

B.

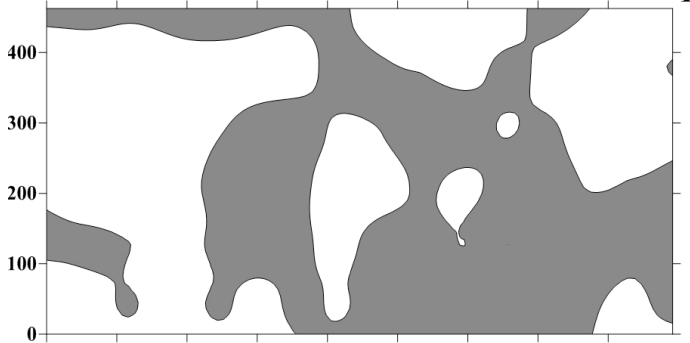

$\stackrel{\text { C. }}{\text {. }}$

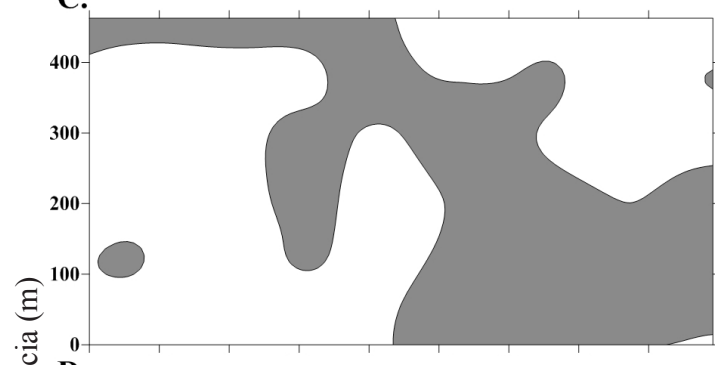

D.

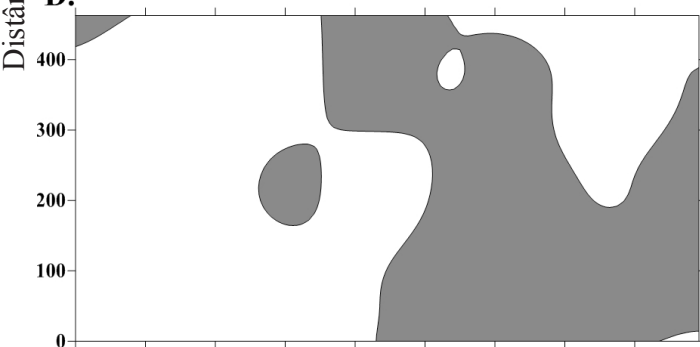

E.

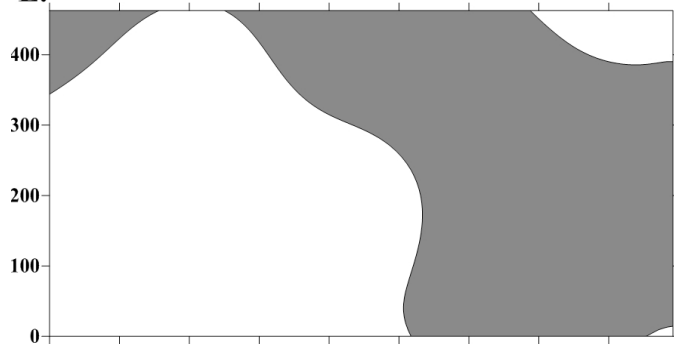

F.

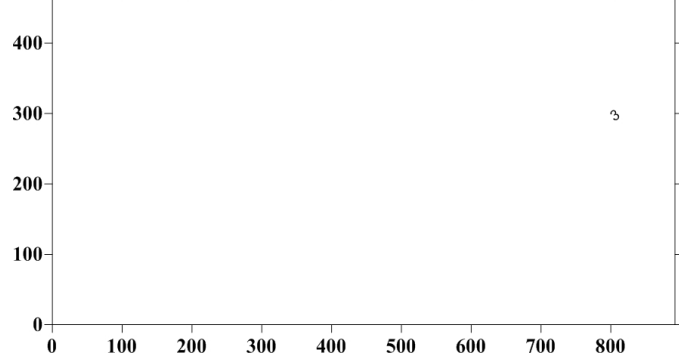

I.

G.

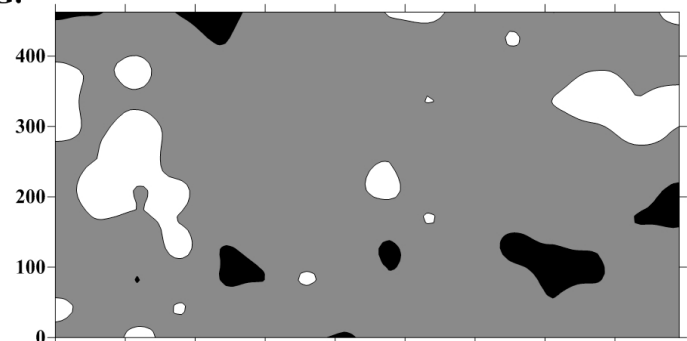

H.
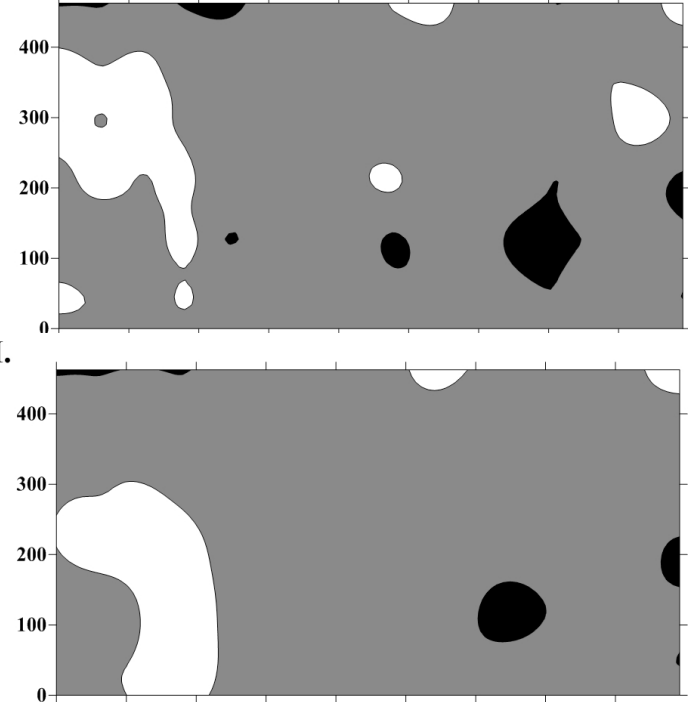

J.

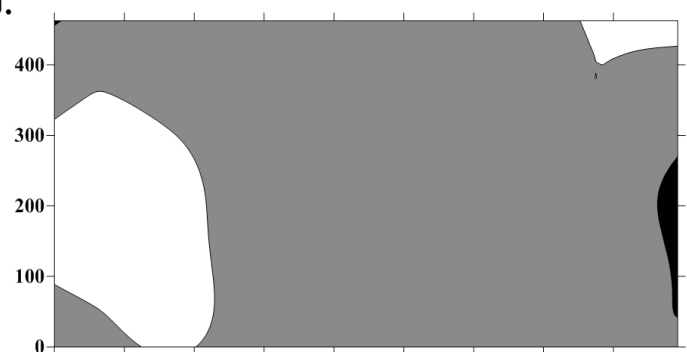

L.

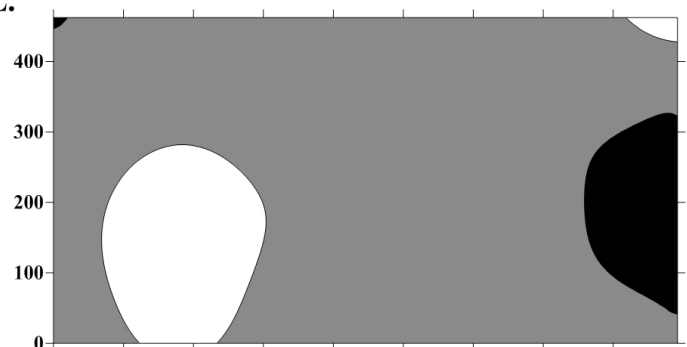

M.

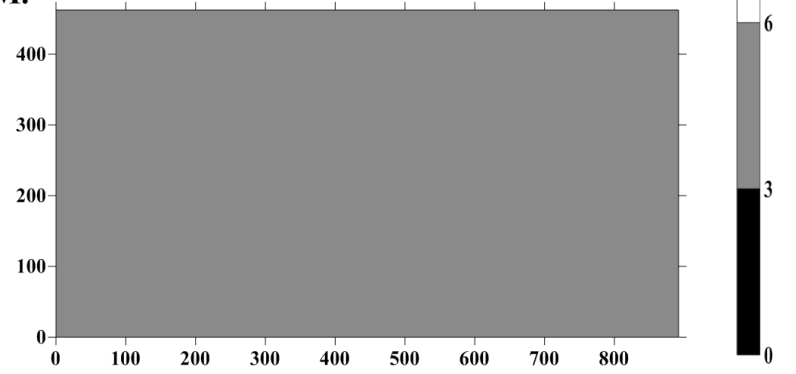

Figura 6. Classes de recomendação de adubação fosfatada para a cultura da soja, na camada 0-10 cm $(A, B, C, D$ E e F) e camada $0-20 \mathrm{~cm}(G, H, I, J, L$ e M) nas densidades amostrais de $1 / 4$ ha $(A$ e $G), 1 / 2$ ha $(B$ e $H), 1$ ha $(C$ e I), 2 ha $(D$ e J), 4 ha $(E$ e L) e 48 ha (F e $M)$ 
A.

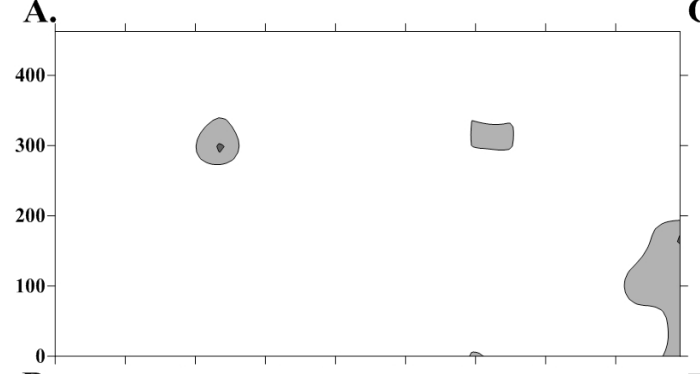

B.

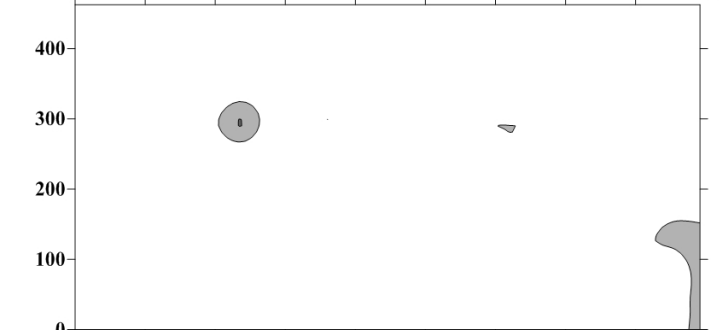

C.

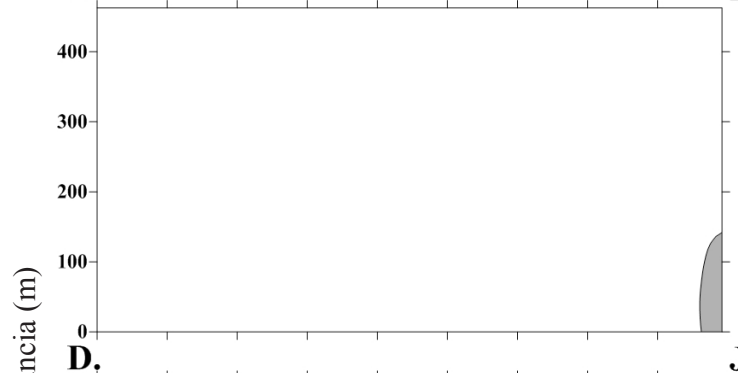

D.

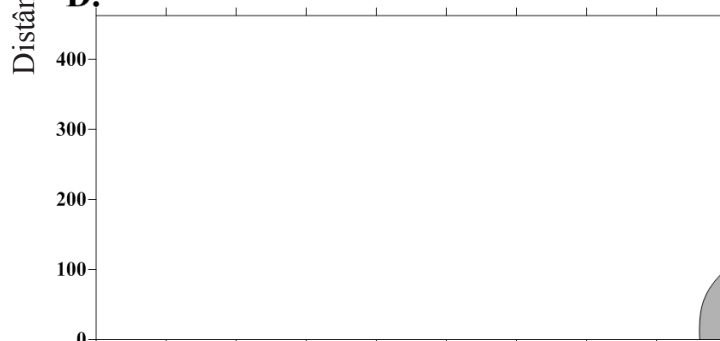

E.

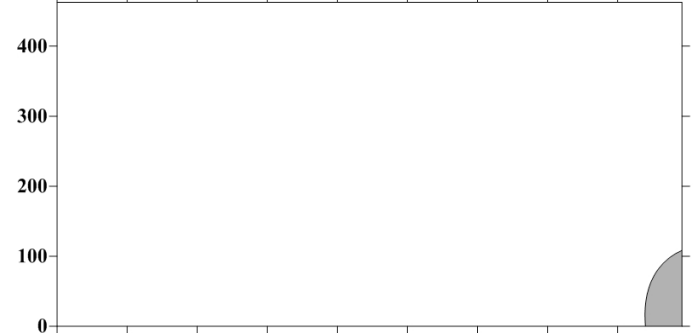

F.

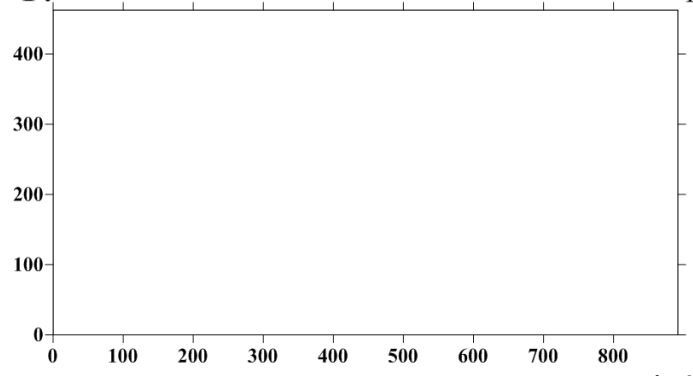

G.

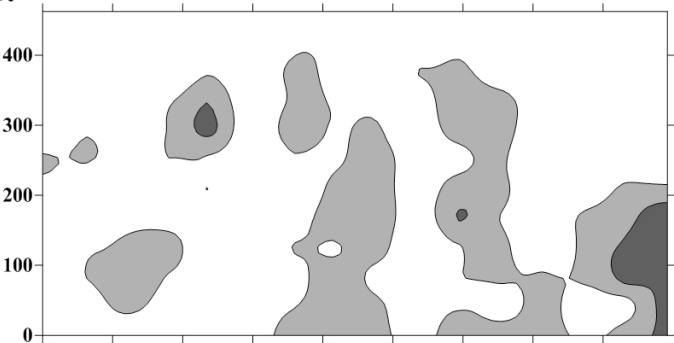

H.

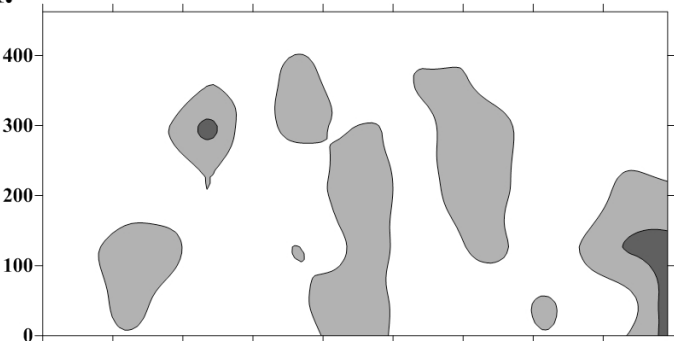

I.

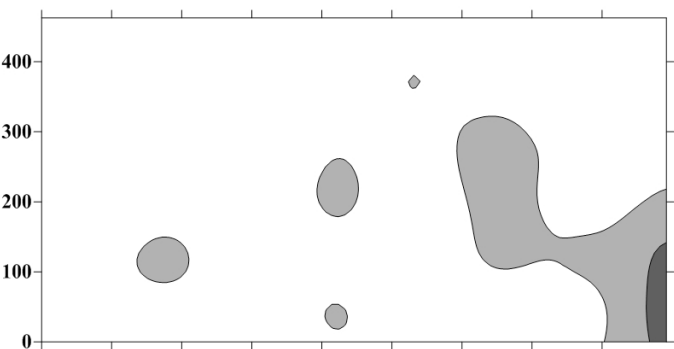

J.

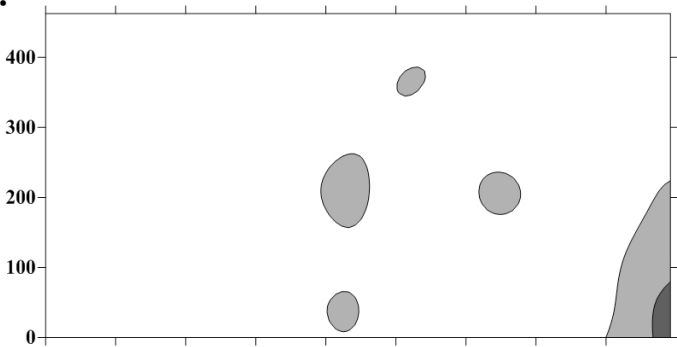

L.

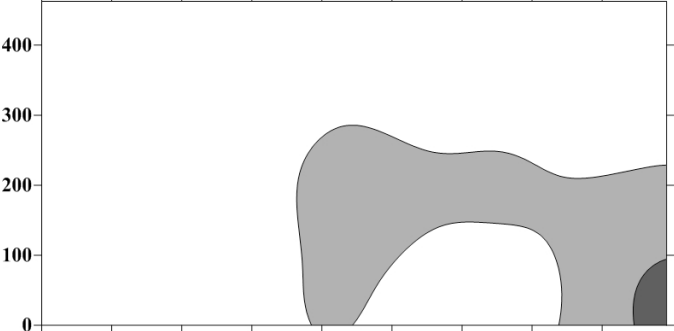

M.

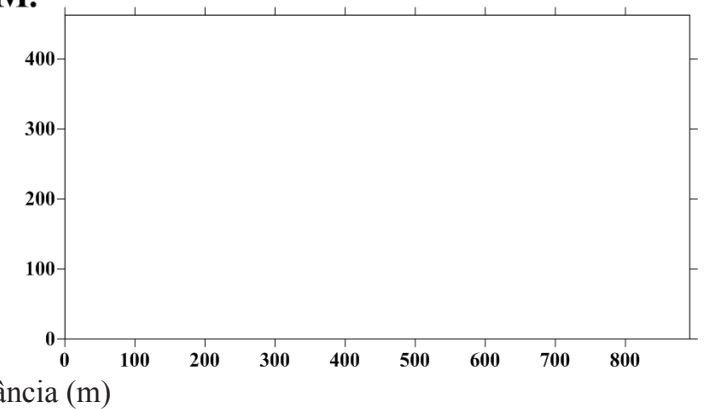

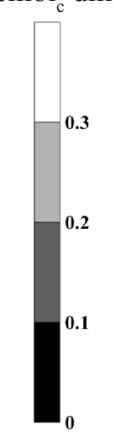

Figura 7. Classes de recomendação de adubação potássica para a cultura da soja na camada 0-10 cm $(A, B, C, D$, E e F) e camada 0-20 cm (G, H, I, J, L e M), nas densidades amostrais de $1 / 4$ ha $(A$ e $G), 1 / 2$ ha $(B$ e $H), 1$ ha $(C$ e I), 2 ha $(\mathrm{D}$ e J), 4 ha (E e L) e 48 ha (F e M) 
com o uso da agricultura de precisão podendo originar certas dúvidas quanto à sua utilização; a questão é que, quando a aplicação apenas das quantidades adequadas se torna maior que a aplicação convencionalmente feita, esta última estava sendo feita de maneira inadequada e sua alteração provavelmente terá resultados positivos.

\section{CONCLUSÕES}

1. Adensidade de uma amostra por hectare é a mais recomendada na elaboração de mapas de atributos químicos do solo.

2. A agricultura de precisão utiliza, de forma mais eficiente, a quantidade de calcário e fertilizantes do que a agricultura convencional.

\section{Literatura CitADA}

Barbieri, D. M.; Marques Júnior, J.; Pereira, G. T. Variabilidade espacial de atributos químicos de um argissolo para aplicação de insumos à taxa variável em diferentes formas de relevo. Engenharia Agrícola, v.28, p.645-653, 2008.

Coelho, F. F.; Giasson, E. Comparação de métodos para mapeamento digital de solos com utilização de sistema de informação geográfica. Ciência Rural, v.40, p.2099-2106, 2010.

Cohen, J. A coeficiente of agreement for nominals scales. Journal of Educational and Measurement, v.20, p.37-46, 1960.

Corá, J. E.; Beraldo, J. M. G. Variabilidade espacial de atributos do solo antes e após calagem e fosfatagem em doses variadas na cultura da cana-de-açúcar. Engenharia Agrícola, v.26, p.374-387, 2006.

Eastman. J. R. Idrisi Taiga tutorial. Worcester: Clark University. 2009. 333p.

EMBRAPA - Empresa Brasileira de Pesquisa Agropecuária. Sistemas de produção 14 - Tecnologias de produção de soja - Região Central do Brasil 2011. Londrina: Embrapa Soja - Embrapa Cerrados - Embrapa Agropecuária Oeste. 2010. 247p.

Ferraz, G. A. E. S.; Silva, F. M.; Carvalho, F. M.; Costa, P. A. N.; Carvalho, L. C. C. Viabilidade econômica do sistema de adubação diferenciado comparado ao sistema de adubação convencional em lavoura cafeeira: Um estudo de caso. Engenharia Agrícola, v.31, p.906-915, 2011.

Fiorio, P. R.; Demattê, J. A. M. Orbital and laboratory spectral data to optimize soil analysis. Scientia Agricola. v.66, p.250-257, 2009.

Golden Software. Surfer versão 9. Tutorial. User's guide, 2010.

Knob, M. J. Aplicação de técnicas de agricultura de precisão em pequenas propriedades. Santa Maria: UFSM, 2006. 129p. Dissertação Mestrado
Landis, J.; Koch, G. G. The measurements of agreement for categorical data. Biometrics, v.33, p.159-179, 1977.

Menegatti, L. A. A.; Molin, J. P.; Goes, S. L.; Korndorfer, G. H.; Soares, R. A. B.; Lima, E. A. Estudo de caso sobre investimento agrícola: Oportunidades com agricultura de precisão. Revista ALCOOLbrás, n.95, p.78-95, 2005.

Nanni, M. R.; Povh, F. P.; Demattê, J. A. M.; Oliveira, R. B.; Chicati, M. L.; Cezar, E. Optimum size in grid soil sampling for variable rate application in site-specific management. Scientia Agricola, v.68, p.386-392, 2011.

Oliveira, R. B.; Lima, J. S. S.; Xavier, A. C.; Passos, R. R.; Silva, S. A.; Silva, A. F. Comparação entre métodos de amostragem do solo para recomendação de calagem e adubação do cafeeiro conilon. Engenharia Agrícola, v.28, p.176-186, 2008.

Passos, A. M. A.; Rezende, P. M.; Alvarenga, A. A.; Baliza, D. B.; Carvalho, E. R.; Alcântara, H. P. Yield per plant and other characteristics of soybean plants treated with kinetin and potassium nitrate. Ciência e Agrotecnologia, v.35, p.965-972, 2011.

Pavan, M. A.; Blach, M. F.; Zempulsky, H. C.; Miyazawa, M.; Zocoler, D. C. Manual de análise química de solo e controle de qualidade. Londrina: IAPAR, 1992. 40p.

Ragagnin, V. A.; Sena Júnior, D. G.; Silveira Neto, A. N. Recomendação de calagem a taxa variada sob diferentes intensidades de amostragem. Revista Brasileira de Engenharia Agrícola e Ambiental, v.14, p.600-607, 2010.

Renó, V. F.; Novo, E. M. L. M.; Almeida Filho, R.; Suemitsu, C. Mapeamento da antiga cobertura vegetal de várzea do baixo amazonas a partir de imagens históricas (19751981) do sensor MSS-Landsat. Acta Amazonica, v.41, p.47-56, 2011.

Robertson, G. P. GS+: Geostatistics for the environmental sciences. Plainwell: Gamma Design Software. 2008. 162p.

Santos, H. C.; Oliveira, F. H. T.; Arruda, J. A.; Lopes, A. R. S.; Souza Júnior, R. F.; Farias, D. R. Amostragem para avaliação da fertilidade do solo em função davariabilidade de suas características químicas. Revista Brasileira de Engenharia Agrícola e Ambiental, v.13, p.849-854, 2009.

Silva, F. A. S.; Azevedo, C. A. V. de. Principal components analysis in the software Assistat-Statistical attendance. In: World Congress on computers in Agriculture, 7, 2009, Reno. Anais... Reno: American Society of Agricultural and Biological Engineers, 2009. CD Rom.

Weirich Neto, P. H.; Sverzut, C. B.; Schimandeiro, A. Necessidade de fertilizante e calcário em área sob sistema plantio direto considerando variabilidade espacial. Revista Brasileira de Engenharia Agrícola e Ambiental, v.10, p.338343, 2006. 